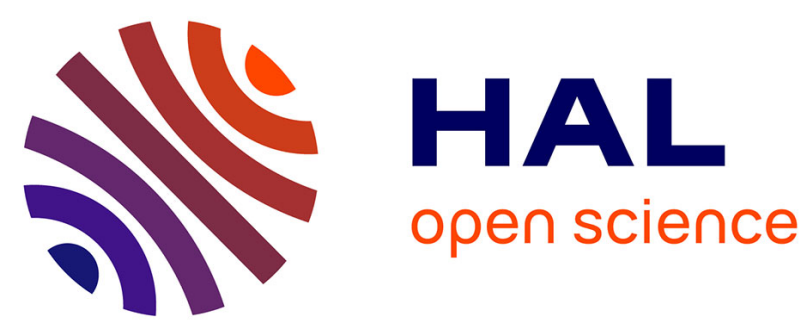

\title{
An Environmental Impact/Cost Model for Evaluating Multiple Feature-Based Machining Methods
}

\author{
Raoudha Gaha, Abdelmajid Benamara, Bernard Yannou
}

\section{To cite this version:}

Raoudha Gaha, Abdelmajid Benamara, Bernard Yannou. An Environmental Impact/Cost Model for Evaluating Multiple Feature-Based Machining Methods. Mnaouar Chouchane, Tahar Fakhfakh, Hachmi Ben Daly, Nizar Aifaoui, Fakher Chaari. Design and Modeling of Mechanical Systems II, Springer, 2015, Lecture Notes in Mechanical Engineering, 978-3-319-17526-3. 10.1007/978-3-31917527-0_3. hal-01712849

\section{HAL Id: hal-01712849 \\ https://hal.science/hal-01712849}

Submitted on 26 Feb 2020

HAL is a multi-disciplinary open access archive for the deposit and dissemination of scientific research documents, whether they are published or not. The documents may come from teaching and research institutions in France or abroad, or from public or private research centers.
L'archive ouverte pluridisciplinaire HAL, est destinée au dépôt et à la diffusion de documents scientifiques de niveau recherche, publiés ou non, émanant des établissements d'enseignement et de recherche français ou étrangers, des laboratoires publics ou privés. 


\title{
An Environmental Impact/Cost model for evaluating Multiple Feature-Based Machining Methods
}

\author{
Raoudha GAHA ${ }^{1}$, Abdelmajid BENAMARA ${ }^{1}$, Bernard YANNOU ${ }^{2}$ \\ , ${ }^{1}$ Laboratoire Genie Mecanique, Ecole Nationale d'Ingenieurs de Monastir, Universite de \\ Monastir, Rue Ibn Aljazzar 5019 Monastir, Tunisia \\ raoudha.gaha@gmail.com , abdel.benamara@enim.rnu.tn \\ 2 Laboratoire Genie Industriel, Ecole Centra Paris, Grande Voie des Vignes \\ 92290 Chatenay-Malabry, France
}

bernard.yannou@ecp.fr

\begin{abstract}
For a designed part, if different sets of features are used for machining, the manufacturing Environmental impacts (EIs)as well as cost may vary. In this research, a new methodology based on feature technology is proposed in order to help designer till detail design phase to choose the most optimal compromise Environmental Impact/Cost in manufacturing process. Hence an Environmental impact/Cost model is presented. This model follow the activities required for machining a set of features which are tool set-ups, fixturing set-ups and machining tool paths. The paper starts by presenting features based models which are the base of the methodology proposed. Then, a state of the art about using Feature technology in reducing on one side manufacturing cost and on the other side manufacturing environmental impacts is presented. Finally an environmental impact/cost methodology for evaluating multiple feature-base machining methods is proposed.
\end{abstract}

Keywords: Environmental evaluation, cost estimation, features technology, detail design, CAD, LCA. 


\section{Introduction}

Today, energy, resources and environmental problems become more and more serious. That's why they are highlighted in regulations frameworks such as WEEE (European Union,, 2003a), RoHS (European Union,, 2003b), EuP (European Union,, 2005) directives and the REACH regulation (European Union,, 2006), which are pushing industrials to adopt sustainable strategies to develop their products.

The eco-design approach, presents, firstly, as a multi-criteria approach taking into account all environmental impacts and secondly, it is also an approach multistep that takes into account all stages of the life cycle. Hence it is largely studied, this last decade, in order to be used in industries. The most studies realized tried to integrate environment constraint in the early design stages such as conceptual design phase which decides about $70 \%-80 \%$ property of the product (Song et al., $2003)$. However, choices done in detailed design phase are responsible on about $80 \%$ of both environmental impacts and costs. How to eco-design in CAD phase with a low cost, if it is possible, is the key for a successful green and less expensive design. After a state of the art on works based on FT to reduce manufacturing cost or EI or both and based on the work of Tseng and Jiang (2000), firstly, in this paper, we put forward the concept of "eco-feature", and then it is used for environmental and cost evaluation in order to choose the most acceptable compromise Environmental impacts/cost. Secondly, a methodology is proposed based on the eco-feature concept. Finally the application of the proposed methodology on a case study is realized.

\section{Features based models}

A feature is a local shape of a product directly related to the manufacturing process. Smith and Dagli (1995) define features as high-level design primitives with their attributes, their qualifiers and restrictions which affect the functionality and/or the ability for the product to be manufactured.

There are different types of features : Shape Features, Constraint Features, Precision Features (or tolerance), Assembly Features, Functional Features, Material Features and Primitive Features.

In combination with surface representation, geometric representation of features shape is oriented to volume representation (3D) such as the representation based on B-REP (Boundary Representation), on CSG (Constructive Solid Geometry), as well as hybrid representation as shown in Wang and Ozsoy (1991).

Techniques developed to create models based on features are divided into two main approaches according to Allada and Anand (1995) and Shah and Mantyla (1995):

- Features recognition: features are recognized from a geometric model applying rules of recognition. More features models, describing the same product, can therefore be derived. 
An Environmental Impact/Cost model evaluating Multiple Feature-Based Machining Methods

- Design features: a product model is developed based on predefined features. In this case, a product's explicit geometry is created from the features model.

To evaluate a part environmentally, non-geometric data has to be attached to the geometric model for eco-designing products in the detail design phase.

\section{State of the art}

Current product development activities in manufacturing companies are still predominantly driven by quality/cost concerns. This does not prevent the existence of some works coupling cost and sustainability. Feature technology (FT) is used in cost estimation of a manufacturing process plan such as cost estimation models of product based on CAD/CAPP integration based on features-based modeling presented in (Tseng and Jiang, 2000),(Shuangxia et al., 2002) (Jinks et al., 2010). In the side of sustainability FT is used to evaluate environmental impacts of manufacturing processes, it is oriented to reducing or avoiding processes which have an impact on ecosystems, human health, etc. Sheng et al. (1995) developed a hierarchical part planning strategy for environmentally conscious machining in order to choose the least impact set of machining sequences order because a feature can be machined with different scenarios. Features are not only used for EE but also for green process planning selection, such as methods developed by Cao et al. (2002) and Tan et al. (2006) for green CAPP selection have to be developed in order to be used as numerical methods integrated in CAD systems and also a method for environmentally conscious process planning proposed by Zhao et al. (2012). Finally FT is also explored in the side of environmental evaluation and cost. In fact, we can find works integrating Life cycle assessment (LCA) to life cycle costing (LCC) such as the novel redesign approach propose by Bovea and Wang (2007) that integrates Quality Function Deployment (QFD) , LCA, life cycle cost (LCC), and contingent valuation (CV). Bevilacqua et al. (2007) also evaluated the environmental impact of circuit board design based on both LCA technique and economic aspects, Kloepffer (2008) proposed a new direction which summarizes environmental LCA, LCC, and Social LCA and the eco-design tool prototype "CAST-tool" developed by Morbidoni et al. (2011). However many disadvantages are detected as high dependence on data accuracy, less intuition of evaluation result, lack of special software and databases and long evaluation cycle, etc. (Xin et al., 2012). Hence, it is necessary to consider environmental and cost constraints of a manufacturing process till feature attribution in detail design phase. 


\section{Proposed methodology}

Our methodology consists in exploring features technology to evaluate the environmental impact (EI) as well as cost of a part manufacturing process till the detail design phase. In fact the influence of geometrical characteristics of a product on reducing the EI was proved on previous works (Gaha et al., 2011) (Gaha et al., 2014). For the cost reducing it is proved by Tseng and Jiang (2000).

According to Tseng and Jiang (2000) there are three activities in manufacturing process that are related to manufacturing costs and can be evaluated:

1. Tool set-ups.

2. Fixturing set-ups.

3. Machining tool paths.

We adopt these activities which can be also evaluated in terms of environmental impacts. Evaluating manufacturing costs and environmental impacts for Multiple Sets of features is a way to localize, the set of features that can be machined with the lowest manufacturing compromise cost Cmin /Environmental impact EImin which is considered a "good" set of features.

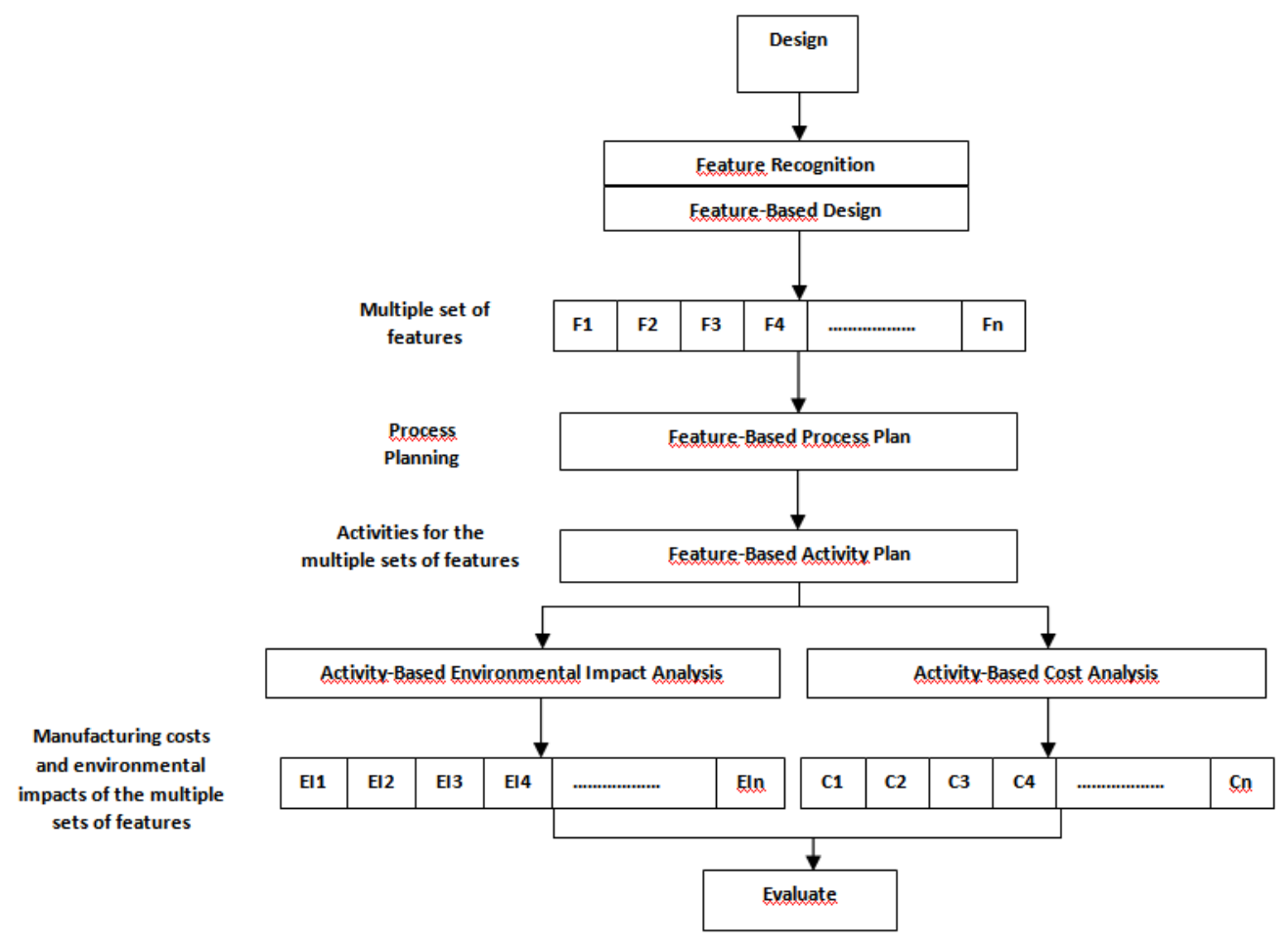

Fig. 1 Proposed methodology based on features technology for cost estimation and environmental evaluations of possible process plans 
Given feature set $\mathrm{Fi}, \mathrm{i}=1, \%$, n, performs the following steps:

1. Calculate tool set-up cost CFSi and environmental impact EIFSi.

2. Calculate fixturing set-up cost CFXi and environmental impact EIFXi .

3. Calculate cost of machining tool paths CFTi and environmental impact EIFTi.

4. The manufacturing cost and Environmental impacts for machining feature set Fi are:

$\mathrm{Ci}=\mathrm{CFSi}+\mathrm{CFXi}+\mathrm{CFTi}$.

$E I_{i}=E I F S i+E I F X i+E I F T i$.

5. Find the smallest in $C i$ as $C \min =\operatorname{Min}\{C i, i=1, \%, n\}$

Find the smallest in EIi as EImin $=\operatorname{Min}\{E I i, i=1, \%, n\}$

6. CFmin is the feature set with the lowest manufacturing cost and EIFmin is the feature set with the lowest manufacturing environmental impact.

So it gives both indications about the cost and about the environmental impact. If we are more interested in eco-design, the best environmental profiles set features is then selected if they are superimposed and we cannot decide then the least expensive set of features is selected

The feature set that can be machined with the lowest activity-based cost/Environmental impact is considered the most suitable method for producing the part.

\section{Conclusion}

This paper is developed base on the work of Tseng and Jiang. It presents and discusses the need for integrating cost and environmental performances into manufacturing process based on feature technology in order to optimize the manufacturing part process in terms of cost as well as environmental impact till detail design phase. In fact, for a given design, different machining scenarios are possible based on different sets of features. Hence manufacturing costs and environmental impacts may vary. A methodology for analyzing different manufacturing costs and environmental impacts for machining using different sets of features were proposed using an activity-based cost/environmental impact model. The activities used in cost and environmental impact analysis were tool set-ups, fixturing set-ups and machining tool paths. 


\section{References}

\section{Journal article}

TSENG, Y.-J. et JIANG, B. C. Evaluating multiple feature-based machining methods using an activity-based cost analysis model. The International Journal of Advanced Manufacturing Technology, 2000, vol. 16, no 9, p. 617-623.

Wang N. and Ozsoy T.M. (1991) A scheme to represent features, dimensions, and tolerances in geometric modeling - Journal of Manufacturing Systems. - 1991. Vol. 10. - pp.233-240 .

Allada V. and Anand S. (1995) Feature-based modelling approaches for integrated manufacturing: state-of-theart survey and future research directions-International Journal of Computer Integrated Manufacturing, Taylor and Francis, 1995. - Vol. 8. - pp. 411--440.

Sheng, P., Srinivasan, M., and Kobayashi, S. (1995). Multi-objective process planning in environmentally conscious manufacturing: a feature-based approach. CIRP AnnalsManufacturing Technology, 44(1), 433-437.

Zhao, F., Murray, V. R., Ramani, K., and Sutherland, J. W. (2012). Toward the development of process plans with reduced environmental impacts. Frontiers of Mechanical Engineering, 1-16.

Bovea, M. D. and Wang, B., "Redesign methodology for developing environmentally conscious Products," Journal of Production Research, Vol. 45, No. 18, pp. 4057-4072, 2007

Bevilacqua, M., Ciarapica, F. E., and Giacchetta, G., "Development of a sustainable product lifecycle in manufacturing firms: a case study," International Journal of Production Research, Vol. 45, No. 18-19, pp. 4073-4098, 2007.

Kloepffer, W., "State-of-the-Art in Life Cycle Sustainability Assessment (LCSA) Life cycle sustainability assessment of products," The International Journal of Life Cycle Assessment, Vol. 13, No. 2, pp. 89-95, 2008.

XIN, Lan-Lan, JIA, Xiu-Jie, LI, Fang-Yi, et al. Green feature modeling for mechanical and electrical product conceptual design. Computer Integrated Manufacturing Systems, 2012, vol. 18, no 4, p. 713-718.

\section{Journal article only by DOI}

H. J. Song and Z. H. Liu, Apr 2003, "Expression of scheme case and scheme generation in product's conceptual design" Journal of Machine Design, vol. 20, no. 4, pp. 9-11.

Smith A. E. and Dagli C. H. (1995) Manufacturing feature identification for intelligent design - Intelligent Systems in Design and Manufacturing. - Boston, MA, USA, 1995. 17-21. - pp. 213--230.

Cao, H. J., Liu, F., He, Y., and Zhang, H. (2002). Study on model set based process planning strategy for green manufacturing. Jisuanji Jicheng Zhizao Xitong/Computer Integrated Manufacturing System(China), 8(12), 978-982.

Tan, X., Liu, F., Dacheng, L., Li, Z., Wang, H., and Zhang, Y. (2006). Improved methods for process routing in enterprise production processes in terms of sustainable development II. Tsinghua Science and Technology, 11(6), 693-700.

GAHA, Raoudha, BENAMARA, Abdelmajid, et YANNOU, Bernard. Eco-design of a basin mixer in geometric modeling phase. Key Engineering Materials, 2014, vol. 572, p. 711.

Book

Shah J. J. and Mantyla M. (1995) Parametric and Feature Based CAD/Cam: Concepts, Techniques, and Applications [Book]. - New York, NY, USA : John Wiley and Sons, Inc., 1995. 
An Environmental Impact/Cost model evaluating Multiple Feature-Based Machining Methods

Online document (no DOI available)

European Union, 2003a. Directive 2002/95/EC of the 27 January 2003 on the restriction of the use of certain hazardous substances in electrical and electronic equipment (European Directive), Official Journal of the European Union.

European Union, 2003b. Directive 2002/96/EC of the 27 January 2003 on waste electrical and electronic equipment (WEEE) (European Directive), Official Journal of the European Union.

European Union, 2005. Directive 2005/32/EC of 6 July 2005 establishing a framework for the setting of ecodesign requirements for energy-using products (European Directive), Official Journal of the European Union.

European Union, 2006. Regulation (EC) n ${ }^{\circ} 1907 / 2006$ of the European Parliament and of the Council of 18 December 2006 concerning the Registration, Evaluation, Authorisation and Restriction of Chemicals (REACH) (European Regulation), Official Journal of the European Union.

Shuangxia, P., Shaofei, J., \& Youzhong, X. (2002). A cost estimation model of product based on CAD/CAPP integration. In Intelligent Control and Automation, 2002. Proceedings of the 4th World Congress on (Vol. 4, pp. 2650-2654). IEEE.

Jinks, S., Scanlan, J., Reed, P., \& Wiseall, S. (2010, December). Utilising dynamic factory simulation to improve unit cost estimation and aid design decisions. In Simulation Conference (WSC), Proceedings of the 2010 Winter(pp. 1758-1766). IEEE.

Gaha, R., Benamara, A., and Yannou, B. (2011), Influence of geometrical characteristics on eco-designed products," Proc. Of the Int. Conf. on Innovation Methods in Product Design 2011, pp. 242-247, 2011.

MORBIDONI, Alessandro, FAVI, Claudio, et GERMANI, Michele. CAD-Integrated LCA Tool: Comparison with dedicated LCA Software and Guidelines for the improvement. In : Glocalized Solutions for Sustainability in Manufacturing. Springer Berlin Heidelberg, 2011. p. 569-574. 